\title{
Domiciliary and Field Work
}

\section{THE TRANSPORT OF HISTOPATHOLOGICAL SPECIMENS BY AIR MAIL}

\author{
R L Jones, Department of Dermatology, Slade Hospital, Headington, Oxford OX3 7JH. \\ J M Ponnighaus, 'LEPRA' Evaluation Project, P O Chilumba, Northern Region, Malawi, \\ Africa.
}

In a previous publication in this journal, $\operatorname{Harman}^{1}$ drew attention to the various stages involved in the selection, excision, fixation, despatch and processing of biopsies in leprosy. During the past 20 years, first in the Department of Human Anatomy in Oxford, and later in the Department of Dermatology, a very considerable number of biopsies from human and animal tissues have been handled and it is a remarkable fact - and a tribute to the postal authorities concerned - that there have been virtually no postal losses. There have, however, been a number of breakages of glass and other containers together with many instances of leakage. Although not bacteriologically hazardous, these have resulted in the loss of important clinical and research material. The use of glass, particularly when small bottles were packed together without adequate packing, often accounted for breakage and leakage, and it was also heavy and thus expensive for airmail posting. Plastic containers of high quality have recently become more generally available and we have found them satisfactory for the preservation and despatch of material from Malawi to Oxford in a series which started in 1979 and has now reached a total of 175 biopsies. Originally these were posted with minimal packing and, although successful, we soon realized that the method did not conform to International or UK Post Office Regulations on the transport of 'perishable biological substances in the Overseas Postal Service'.2 These regulations require that non-living pathological material 'must be packed in an inner impermeable container with an outer protective container and with absorbent material placed either in the inner container, or between the outer and inner containers. This material must be of sufficient quantity to absorb, in case of breakage, all the liquid contained in the inner container, and the contents of both inner and outer containers must be packed in such a way as to prevent any movement.'

More recently, a re-usable, high impact plastic postal box has come on to the market which has been designed specifically for the transport of pathological specimens. ${ }^{3}$ This box measures $107 \mathrm{~mm} \times 65 \mathrm{~mm} \times 34 \mathrm{~mm}$ deep and will comfortably hold two plastic "universal bottles' ${ }^{4}$ together with sufficient material to absorb all the fixative in the event of breakage. It has a sliding lid which can be opened easily for official inspection and is secured at one end by a plastic clip.

In the above series from Malawi, biopsies have usually been taken with 4-mm punch and then placed in 1.5-ml polypropylene tubes with push-on lids, ${ }^{5}$ having a diameter of $9.5 \mathrm{~mm}$ and a depth of $39 \mathrm{~mm}$. Each tube need contain only $1 \mathrm{ml}$ of fixative, as this is more than sufficient to keep the biopsy moist. Larger, elliptical biopsies can also be accommodated in these tubes satisfactorily. Three tubes are then placed inside a plastic 'universal' bottle giving a total of 6 biopsies per box (Fig. 1). This added precaution, we believe, may minimize the chances of changing temperature, atmospheric pressure or vibration from loosening the lids of the plastic tubes. We have found this method of transport entirely satisfactory for biopsies, and the box may also be used, with appropriate packing, for the despatch of glass slides carrying cut sections. 


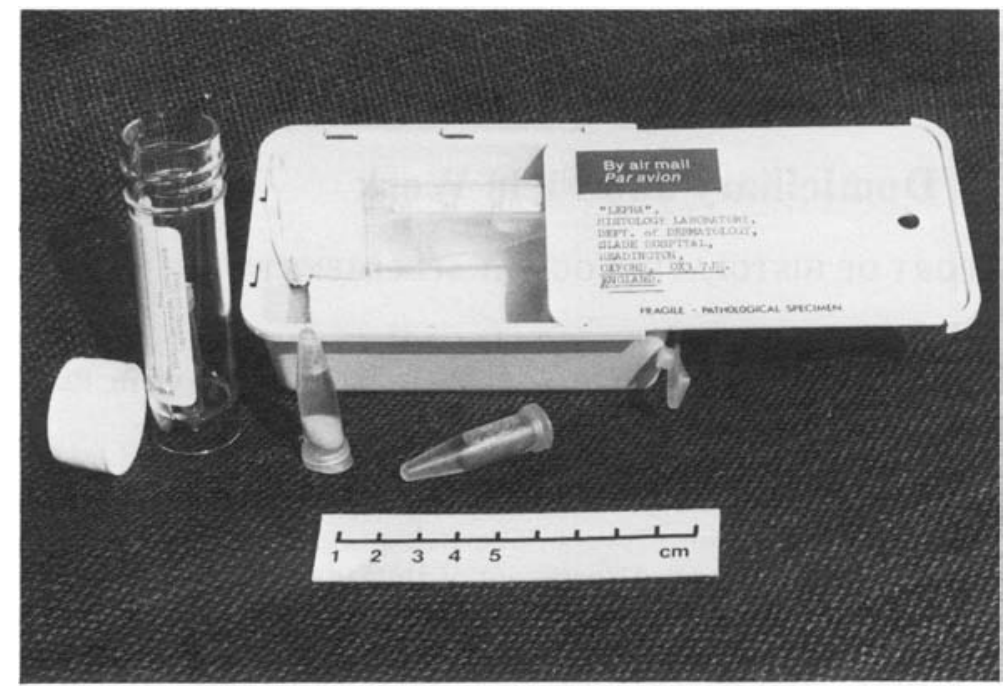

Figure 1. Re-usable plastic postal box, 'universal' containers and polypropylene stoppered tubes. Parcel weight (including 6 biopsies) $=110 \mathrm{~g}$ (maximum).

In the UK, the Post Office requires users to submit a sample pack for inspection in order to ensure that it complies with the regulations; unless this is done, packs which do not comply may be intercepted and destroyed. It is advisable for workers in other countries to follow a similar procedure with their own postal service. The costs of the materials involved are as follows:

Re-usable postal box (each)

$£ 1.05$

Plastic 'universal' bottle (2)

$£ 0.13$

Polypropylene stoppered tube (6) £0.08

(The latter two items are usually supplied by the manufacturers in bulk only, but they should be obtainable from hospitals and laboratories in small quantities.)

We have found this arrangement to be simple and practical to use and relatively cheap for the despatch of biopsies from Africa to the UK, and of stained slides in the other direction. Needless to say, the plastic boxes and 'universal' containers can be used over and over again, but we advise discarding the stoppered tubes when leprosy is suspected in view of the possibility of contamination of further specimens by acid-fast bacilli.

\section{Acknowledgement}

Jones RL and Ponnighaus JM are both supported by grants from LEPRA.

\section{References}

Harman DJ. Biopsies in Leprosy. Field Workers Forum. Lepr Rev, 1975;46;125-134. Post Office Regulation PHQ 3845M, 200.11.75. LE (The United Kingdom).

The Kemble Instrument Company Ltd., Albert Drive, Burgess Hill, Sussex.

Sterilin Ltd., 43/45 Broad Street, Teddington, Middlesex, England TW1 18 QZ.

Camlab Ltd, Nuffield Road, Cambridge, England CB4 1 TH. 